Echt, C. S. (1999): Use of microsatellite markers in management of conifer forest species. In: Douglas, G. C., ed. Strategies for improvement of forest trees. Dublin, Ireland: COFORD National Council for Forest Research and Development: 75-82.

Echt, C. S., G. G. Vendramin, C. D. Nelson and P. MaRQUARDT (1999): Microsatellite DNA as shared genetic markers among conifer species. Can. J. For. Res. 29: 365-371.

Edwards, K. J., J. H. A. Barker, A. DAly, C. Jones and A. KARP (1996): Microsatellite libraries enriched for several microsatellite sequences in plants. BioTechniques 20: 758-760.

GuPtA, A. K., B. Y. KANG, J. K. RoY and O. P. RAJORA (2005): Large scale development of selectively amplified microsatellite polymorphic loci (SAMPL) markers in spruce (Picea). Molecular Ecology notes 5 (3): 481.

Hamilton, M. B., E. L. Pincus, A. Di Fiore and R. FleiSHER (1999): Universal linker and ligation procedures for construction of genomic DNA libraries enriched for microsatellites. BioTechniques 27: 500-507.

Hodgetts, R. B., M. A. Aleksiuk, A. Brown, C. Clarke, E. MacDonald, S. Nadeem and D. Khasa (2001): Development of microsatellite markers for white spruce (Picea glauca) and related species. Theor. Appl. Genet. 102: $1252-1258$.

LIU, K. J. and S. V. Muse (2005): PowerMarker: an integrated analysis environment for genetic marker analysis. Bioinformatics 21: 2128-2129.

Mehes, M., K. K. Nkongolo and P. Michael (2007): Genetic analysis of Pinus monticola and Pinus strobes using microsatellites. Poster presented at the joint annual meeting of the Canadian Genetic Society of
Canada and Canadian Fly Society in Montreal (Qc), June 18-22.

Nkongolo, K. K., P. Michael and T. Demers (2005): Application of ISSR, RAPD, and cytological markers to the certification of Picea mariana, P. glauca, and $P$. engelmannii trees and their putative hybrids. Genome 48: 302-311.

Pfeiffer, A., A. M. Olvieri and M. Morgante (1997): Identification and characterization of microsatellites in Norway spruce (Picea abies K.). Genome 40: 411-419.

RAJORA, O. P., M. H. RHAMAN, S. DAYANANDAN and A. Mosseler (2001): Isolation, characterization, inheritance and linkage of microsatellite DNA markers in white spruce and their usefulness in other spruce species. Mol. Gen. Genet. 264: 871-882.

Ranger, M., K. VAndeligt, P. Michael, K. K. Nkongolo and P. BECKETT (2007): Microsatellite and ISSR analysis of Pinus banksiana and Pinus resinosa from metal contaminated areas in the Greater Sudbury region. Paper presented at the Mining and Environment IV Conference in Sudbury (ON), October 19-27.

Scotti, I., G. P. Paglia, F. Magni and M. Morgante (2002): Efficient development of dinucleotide microsatellite markers in Norway spruce (Picea abies Karst.) through dot-blot selection. Theor. Appl. Genet. 104: 1035-1041.

Wang, Y., J. Luo, X. Xue, H. Korpelainen and C. Li (2005): Diversity of microsatellite markers in the populations of Picea asparta originating from the mountains of China. Plant Science 168: 707-714.

YEH, F. C. and T. J. B. BoYLE (1997): Population genetic analysis of co-dominant and dominant markers and quantitative traits. Belg. J. Bot. 129: 157.

\title{
Phenotypic Selection of Calycophyllum spruceanum on Farms in the Peruvian Amazon: Evaluating a Low-Intensity Selection Strategy
}

\author{
By John C. Weber ${ }^{\left.1,3,{ }^{*}\right)}$, Carmen Sotelo Montes ${ }^{1,3)}$, Julio Ugarte ${ }^{1)}$ and Tony Simons ${ }^{2)}$
}

(Received $4^{\text {th }}$ August 2008)

\begin{abstract}
A low-intensity selection strategy was recommended for timber trees in the Peruvian Amazon to maintain genetic variation on farms and produce modest gains in tree growth. The effectiveness of this strategy was evaluated using Calycophyllum spruceanum. Farmers selected 66 mother trees of different ages on farms in

\footnotetext{
1) World Agroforestry Centre (ICRAF), CIP, Apartado Postal 1558, Lima 12, Peru.

2) World Agroforestry Centre (ICRAF), P.O. Box 30677-00100, Nairobi, Kenya.

${ }^{3}$ ) World Agroforestry Centre (ICRAF), West and Central Africa Regional Office, B.P. E5118, Bamako, Mali.

*) Author for correspondence: John C. WeBER. Telephone: (223) 2223375, fax: (223) 2228683. E-Mail: johncrweber@aol.com
}

seven locations ( $\sim 20 \%$ of all trees in the locations) in one watershed, based on a visual assessment of growth, form and external disease symptoms. Another 66 mother trees were chosen at random. Tree height, stem diameter, stem bifurcations and mortality of progeny of the selected and random groups of mother trees were evaluated at 15, 26 and 38 months in a provenance/progeny test located on farms in the same watershed. Height was significantly greater $(10 \%)$ in the selected group at 15 months, but it did not differ significantly between the selected and random groups at 26 and 38 months. There were no significant differences in diameter, bifurcations and mortality between the groups. There was significant variation in height and diameter at all measurement ages due to families, and results suggested that variation in bifurcations and mortality due to families was also significant. Based on approximate $95 \%$ confidence 
intervals, family variances in height and diameter did not differ significantly between the selected and random groups at any measurement age, but evaluations should continue to confirm these tentative conclusions. Some practical implications for tree improvement programs are discussed.

Key words: tropical timber tree improvement, genetic variation, growth, form, mortality.

\section{Introduction}

Farms are the principal sources of tree seed for planting in agroforestry systems in the Peruvian Amazon (BRODIE et al., 1997). Farmers typically select a few trees on their farms for seed collection based on the tree's phenotypic characteristics for the desired product. Selecting a small proportion of the trees should lead to greater gain but, all other things being equal, it will also lead to greater reduction in genetic variation in the next generation. Reduced genetic variation could lower the tree population's adaptability to changing environments, and limit opportunities to select germplasm in response to changes in consumer demands (SIMONs et al., 1994). In the process of developing tree improvement strategies with farming communities in the Peruvian Amazon, O'NEILL et al. (2001) recommended low selection intensities, i.e. selecting a relatively large proportion of the trees on farms. The objective was to maintain greater genetic variation in agroforestry systems and produce modest genetic gains.

This paper assesses the effectiveness of this lowintensity selection strategy, using Calycophyllum spruceanum (Bentham) Hooker f. ex Shumann (Rubiaceae family) as a case study. Farmers rank C. spruceanum as a priority timber tree for agroforestry systems in the Peruvian Amazon (WeBER et al., 2001). It is a pioneer species that colonizes the alluvial floodplain and other disturbed sites in the lowland humid tropical forests of Brazil, Peru, Ecuador and Colombia (LINARES et al., 1992). Trees in natural stands can attain heights of $35 \mathrm{~m}$ with stem diameters of $1.8 \mathrm{~m}$ at breast height (SEARS, 2003). Stems can be harvested for construction poles after 2 to 3 years, or sawn timber after 15 to 20 years, and then coppiced for successive harvests. The wood is in demand in national and international markets for furniture, wall paneling and parquet (TOLEDO and RINCón, 1996), and is valued for charcoal because of its high heat content (Sotelo Montes et al., 2003). There is considerable geographic and genetic variation in tree growth and wood properties, which could be useful for tree improvement programs (SOTELO MONTES et al., 2003; BoIvin-CHABOT et al., 2004; WeBER and Sotelo Montes, 2005; Sotelo Montes et al., 2006, 2007a, 2007b, 2008).

The objectives of this study were (a) to determine if there were significant differences in growth, stem bifurcations and mortality of progeny from two groups of trees - one group phenotypically selected using a lowintensity selection strategy, and the other randomly selected; and (b) to assess whether family variance in growth traits was similar in the selected and random groups. The effectiveness of phenotypic selection has been evaluated in several temperate-zone timber species (CoRNELIUS, 1994), based primarily on selections in even-aged plantations. To our knowledge, this is the first published report of a study to assess the effectiveness of farmers' phenotypic selection of a tropical timber species growing in uneven-aged stands on farms. Some practical implications and recommendations are discussed.

\section{Materials and Methods}

\section{Sample region, study area, experimental design and management of the provenance / progeny test}

The sample region and study area are located in the Aguaytía watershed in the western Peruvian Amazon (Figure 1). In general, rainfall and soil fertility increase from the lower to the upper parts of the watershed (Sotelo Montes et al., 2006). Open-pollinated seeds were collected in September-October 1998 from 132 mother trees growing on farms in seven locations (provenances) in the lower, middle and upper parts of the watershed (Figure 1). Based on a visual rather than a quantitative assessment, farmers selected 66 mother trees ( $20 \%$ of the trees in each provenance) that appeared to have above-average growth rates, good bole form and no external disease symptoms. Since selection was based on several traits, this was not truncation selection for any one trait (FALCONER and MACKAY, 1996). In addition, 66 other mother trees were selected at random. These are referred to hereafter as the selected and random groups of trees. To reduce the chance of sampling siblings, at least $100 \mathrm{~m}$ was maintained between any two sampled trees. Although the number of trees was the same for both groups $(7,7,9$ 14, 3, 17 and 9, respectively for provenance codes 1 to 7 ), the selected and random trees were not paired samples. The age of the trees could not be determined with certainty, but they were definitely not all of the same age.

Seedlings of the 132 mother trees (families) were grown in the nursery in a replicated experimental design similar to that used in the field (described below). After 15 months, they were transplanted into the provenance/progeny test. Due to heavy rains and flooding, transplanting extended over a 2-month period and this undoubtedly contributed to the variation among replications.

The provenance/progeny test was established in the lower, middle and upper parts of the Aguaytía watershed, hereafter called planting zones (Figure 1). The experimental design was a randomized complete block with split plots. Ten replications were established on different farms: three each in the lower and middle planting zones, and four in the upper zone. The test was not replicated within farms. In each replication, the selected and random groups were randomly assigned to two main plots, and the families in each group were randomly assigned to 66 sub plots, each containing two trees. Spacing was 2.5 by $2.5 \mathrm{~m}$ within and between rows. Two rows of border trees surrounded each main plot. Dead trees were replaced during the first dry season: replants were not included in the analyses of tree growth and stem bifurcations. 


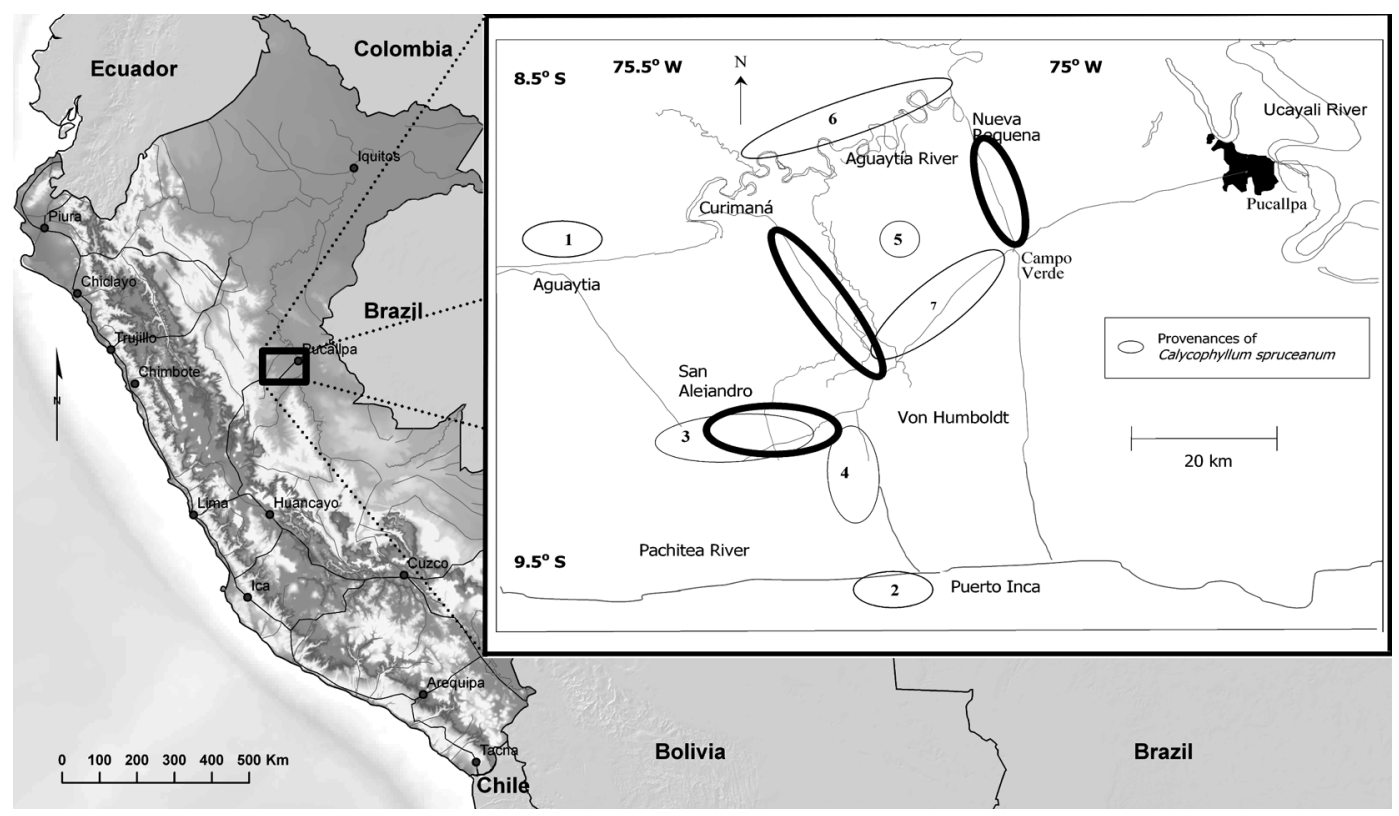

Figure 1. - Geographic location of the sample region and study area in the Aguaytía watershed of the Peruvian Amazon: inset shows the location of the seven provenances of Calycophyllum spruceanum and the three planting zones (bold circles).

Management practices included a cover crop, fertilizer application and manual weeding. A leguminous herbaceous cover crop, Centrosema macrocarpum Benth., was sown between rows and $5 \mathrm{~m}$ around the perimeter of each replication. Organic compost $(1 \mathrm{~kg})$ and rock phosphate $(200 \mathrm{~g})$ were placed in each planting hole; and inorganic nitrogen, phosphorous and potassium (70 g N, $185 \mathrm{~g} \mathrm{P}, 100 \mathrm{~g} \mathrm{~K})$ were applied around each tree 22 and 34 months after planting. Farmers weeded their replications approximately every 4 weeks during the rainy season and every 6-8 weeks during the dry season. They could do this in 2-3 days when they had available time and labor, but it took longer during periods of peak demand on their time and labor. As a result, weeding was not systematically done and this contributed to the variation among and within replications.

\section{Data collection and statistical analysis}

Trees were evaluated at 15, 26 and 38 months. Tree height was measured to the nearest $\mathrm{cm}$ using a meter stick or telescopic measuring pole. Stem diameter at 10 $\mathrm{cm}$ above ground was measured to the nearest $0.1 \mathrm{~cm}$ using callipers or diameter tape. The proportions of dead trees and trees with stem bifurcations were calculated for the selected and random groups in each replication.

The SAS $^{\circledR}$ statistical package version 9.1 (SAS INSTITUTE INC., 2004) was used for all statistical analyses. Departure from the normal distribution and homogeneity of variance were tested for the residuals using statistics provided by the UNIVARIATE procedure. The angular transformation (arcsin $\sqrt{ } \mathrm{p}$ ) was applied to the proportions of mortality and stem bifurcations, but transformations were not considered necessary for tree height and stem diameter because the residuals had a normal distribution and homogeneous variance. The significance level for all tests was $\alpha \leq 0.05$.

Analysis of variance at each measurement age was carried out using the MIXED procedure (restricted maximum likelihood estimation method). Variation was analyzed using a split-plot model in a randomized complete block design. Analyses of tree height and stem diameter included the following sources of variation: planting zone $(Z)$, replication nested in zone $[R(Z)]$, group $(G$, selected or random), provenance $(\mathrm{P})$, family nested in provenance and group $[\mathrm{F}(\mathrm{PG})]$, interactions $[\mathrm{G} \times \mathrm{Z}, \mathrm{G} \times$ $R(Z), P \times Z, P \times R(Z), P \times G, F(P G) \times Z, F(P G) \times R(Z)$, and residual variation between the two trees within subplots. Analyses of mortality and stem bifurcations included $\mathrm{Z}, \mathrm{R}(\mathrm{Z}), \mathrm{G}, \mathrm{G} \times \mathrm{Z}$, and $\mathrm{G} \times \mathrm{R}(\mathrm{Z})$. The significance of effects due to fixed factors ( $\mathrm{Z}, \mathrm{G}$ and $\mathrm{G} \times \mathrm{Z}$ ) was tested with $F$ ratios. For random factors, the $Z$ test was used to determine if the variance component was significantly greater than zero. Variance components were expressed as a percentage (VC\%) of the total phenotypic variance, which was defined as the sum of all variance components except those for $R(Z)$ and $G \times R(Z)$.

The likelihood ratio chi-square statistic $\left(G^{2}\right.$, FREQ procedure) was used to test whether the frequencies of stem bifurcations and mortality at each measurement age were statistically independent of families. The row variable was families and the column variables were (a) the number of trees with and without stem bifurcations, and (b) the number of dead and living trees. Independence was tested for all families, and separately for families in the selected and random groups.

Variance components due to families $\left(\sigma_{F(P G)}^{2}\right)$ and their coefficients of variation $\left(\sqrt{ } \sigma_{F(P G)}^{2}\right.$ divided by the group mean) were evaluated in the selected and random 
groups at each measurement age. These are hereafter called family variance and coefficient of family variation, respectively.

The sample sizes in this test could have reduced the accuracy of some estimates of means and variances. The numbers of progeny per family (maximum 20) and families per provenance (3-17) were low, reducing the accuracy of estimates of family means and some provenance means. In addition, a minimum sample size of 40 is recommended to obtain accurate estimates of variance components (N. Mandel, personal communication). The number of families was adequate to obtain an accurate estimate of family variance, but the number of provenances was too low to obtain an accurate estimate of provenance variance.

\section{Results}

\section{Variation in tree growth, form and mortality}

Mean tree height and stem diameter were greater in the selected than in the random group at all measurement ages (Table 1). The difference was approximately $10 \%$ at 15 months, but decreased to only $1 \%$ at 38 months. The only significant difference was in height at 15 months (Table 2).

The random group had higher mortality than the selected group, and the difference increased from $2 \%$ to $7 \%$ between 15 and 38 months (Table 1). These differences, however, were not significant (Table 2). The increase in mortality in the random group over time occurred primarily in two replications located in the drier planting zones (lower and middle).
There was no consistent or significant difference in stem bifurcations between the selected and random groups at any measurement age (Tables 1,2).

Planting zones produced increasingly greater significant differences in tree height and stem diameter from 15 to 38 months (Table 2). In contrast, there was no significant difference in the proportions of stem bifurcations or mortality among the planting zones.

There was significant variation in tree height and stem diameter due to families at all measurement ages (Table 2), but this accounted for less than $10 \%$ of the total phenotypic variance $(\mathrm{VC} \%)$. Variation due to provenances was not significant at any age. Most of the phenotypic variance was due to the family by replication interaction and residual variation.

The frequencies of stem bifurcations and tree mortality were not randomly distributed among families (Table 3). There was a significant lack of independence between stem bifurcations and the 132 families at 26 months: tests within each group indicated that families in the selected group contributed primarily to this lack of independence. A significant lack of independence between mortality and the 132 families was observed at all measurement ages, and this was also primarily due to families in the selected group.

\section{Family variance in growth traits in the selected and random groups}

Family variances $\left(\sigma_{F(P G)}^{2}\right)$ and their coefficients of variation for tree height and stem diameter were slightly greater in the selected group at 15 months, similar in the two groups at 26 months, and notably lower in the

Table 1. - Descriptive statistics of tree height, stem diameter, stem bifurcations and tree mortality of Calycophyllum spruceanum in the random and selected groups of trees at 15, 26 and 38 months.

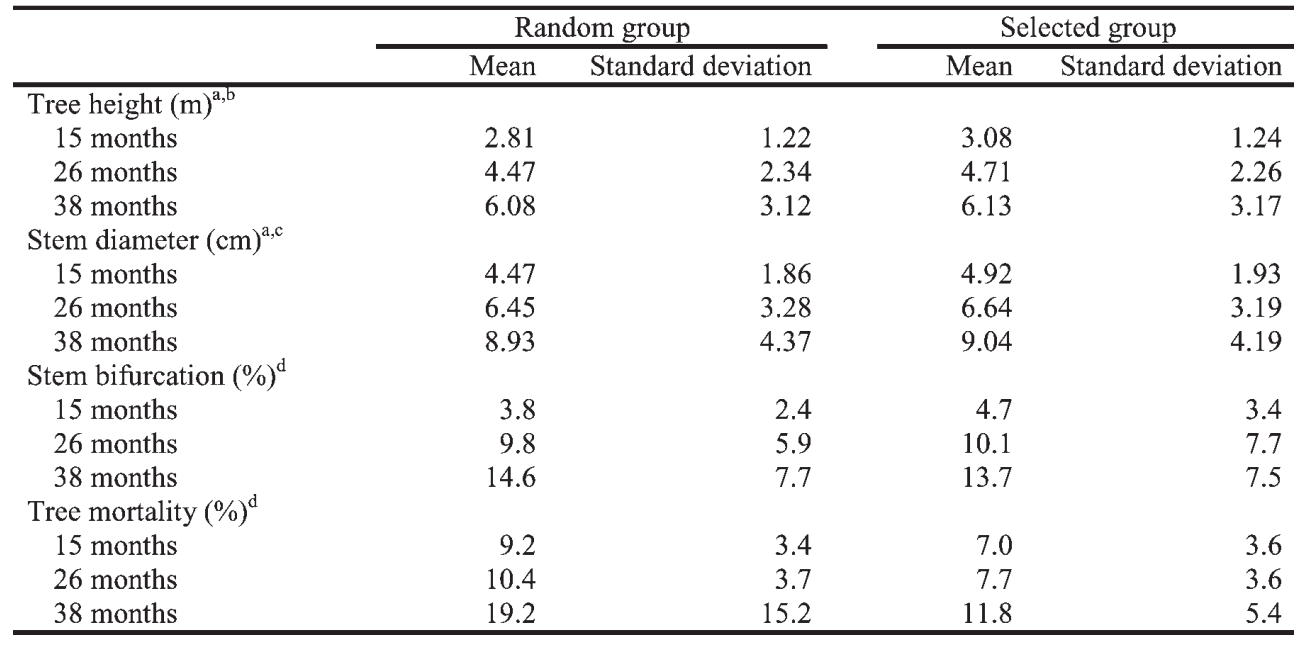

a Number of trees at 15, 26 and 38 months, respectively = 1181, 1165 and 1049 for the random group, and 1227, 1219 and 1164 for the selected group.

b Tree height differed significantly between random and selected groups at 15 months only (Table 2).

c Stem diameter at $10 \mathrm{~cm}$ above ground level. No significant difference between random and selected groups (Table 2).

d Percentage of trees with bifurcations and dead trees per replication: number $=10$ replications for both random and selected groups at 15, 26 and 38 months. No significant difference between random and selected groups (Table 2). 
selected group at 38 months (Table 4). Given the large standard errors for $\sigma_{F(P G)}^{2}$, it is unlikely that there were statistically significant differences in $\sigma_{F(P G)}^{2}$ between the two groups, especially at 15 and 26 months. The variance component \pm 2 standard errors is an approximate $95 \%$ confidence interval for the variance component (OEHLERT, 2000). At 38 months, when the largest differences were observed, the approximate confidence intervals in the random and selected groups, respectively were $0.010-0.282$ and $0.000-0.183$ for height, and
$0.108-0.804$ and $0.000-0.358$ for diameter. Given the overlap between the intervals $(0.010-0.183$ for height, and $0.108-0.358$ for diameter), we cannot conclude that the differences are statistically significant. The coefficient of family variation, which adjusts for differences in means between groups, was approximately $25 \%$ and $40 \%$ lower for height and diameter, respectively in the selected than in the random group at 38 months. The coefficient of variation is calculated from the family variance and the group mean, so its standard error

Table 2. - Analysis of variance of tree height, stem diameter, stem bifurcations and tree mortality of Calycophyllum spruceanum at 15,26 and 38 months.

\begin{tabular}{|c|c|c|c|c|c|c|c|c|c|c|c|c|}
\hline \multirow[t]{2}{*}{ Source of variation $^{\mathrm{a}}$} & $\mathrm{P}^{\mathrm{b}}$ & $\mathrm{VC} \%^{\mathrm{c}}$ & $\mathrm{P}$ & $\mathrm{VC} \%$ & $\mathrm{P}$ & $\mathrm{VC} \%$ & $\mathrm{P}$ & $\mathrm{VC} \%$ & $\mathrm{P}$ & $\mathrm{VC} \%$ & $\mathrm{P}$ & $\mathrm{VC} \%$ \\
\hline & \multicolumn{2}{|c|}{ Height -15} & \multicolumn{2}{|c|}{ Height -26} & \multicolumn{2}{|c|}{ Height -38} & \multicolumn{2}{|c|}{ Diameter -15} & \multicolumn{2}{|c|}{ Diameter -26} & \multicolumn{2}{|c|}{ Diameter -38} \\
\hline \multicolumn{13}{|l|}{$\underline{\text { Farms }}$} \\
\hline $\bar{Z}$ & 0.052 & - & 0.003 & - & $<0.001$ & - & 0.036 & - & 0.001 & - & $<0.001$ & - \\
\hline $\mathrm{R}(\mathrm{Z})$ & 0.035 & - & 0.036 & - & 0.040 & - & 0.035 & - & 0.041 & - & 0.038 & - \\
\hline \multicolumn{13}{|l|}{ Main plot } \\
\hline $\bar{G}$ & 0.020 & - & 0.133 & - & 0.318 & - & 0.084 & - & 0.621 & - & 0.376 & - \\
\hline $\mathrm{G} \times \mathrm{Z}$ & 0.501 & - & 0.588 & - & 0.988 & - & 0.715 & - & 0.698 & - & 0.504 & - \\
\hline $\mathrm{G} \times \mathrm{R}(\mathrm{Z})$ & 0.055 & - & 0.063 & - & 0.063 & - & 0.060 & - & 0.051 & - & 0.098 & - \\
\hline \multicolumn{13}{|l|}{ Subplot } \\
\hline $\mathrm{P}$ & 0.110 & 2.7 & 0.121 & 2.6 & 0.214 & 0.9 & 0.339 & 1.2 & 0.185 & 1.2 & 0.343 & 0.9 \\
\hline $\mathrm{P} \times \mathrm{Z}$ & 0.373 & 0.2 & 0.242 & 0.5 & 0.335 & 0.3 & - & 0.0 & - & 0.0 & - & 0.0 \\
\hline$P \times R(Z)$ & 0.171 & 0.8 & 0.328 & 0.3 & 0.235 & 0.8 & 0.481 & 0.1 & - & 0.0 & 0.264 & 0.5 \\
\hline$P \times G$ & - & 0.0 & - & 0.0 & - & 0.0 & 0.180 & 3.5 & 0.295 & 3.5 & 0.284 & 1.9 \\
\hline $\mathrm{F}(\mathrm{PG})$ & $<0.001$ & 8.6 & $<0.001$ & 9.1 & $<0.001$ & 5.3 & $<0.001$ & 3.5 & $<0.001$ & 3.5 & $<0.001$ & 6.3 \\
\hline $\mathrm{F}(\mathrm{PG}) \times \mathrm{Z}$ & 0.394 & 0.5 & - & 0.0 & - & 0.0 & - & 0.0 & - & 0.0 & - & 0.0 \\
\hline $\mathrm{F}(\mathrm{PG}) \times \mathrm{R}(\mathrm{Z})$ & $<0.001$ & 23.2 & $<0.001$ & 33.2 & $<0.001$ & 33.9 & $<0.001$ & 32.8 & $<0.001$ & 32.8 & $<0.001$ & 31.6 \\
\hline \multirow[t]{2}{*}{ Residual } & $<0.001$ & 64.0 & $<0.001$ & 54.3 & $<0.001$ & 58.8 & $<0.001$ & 52.9 & $<0.001$ & 59.0 & $<0.001$ & 58.8 \\
\hline & \multicolumn{2}{|c|}{ Bifurcation $^{\mathrm{d}}-15$} & \multicolumn{2}{|c|}{ Bifurcation -26} & \multicolumn{2}{|c|}{ Bifurcation -38} & \multicolumn{2}{|c|}{ Mortality $^{\mathrm{d}}-15$} & \multicolumn{2}{|c|}{ Mortality -26} & \multicolumn{2}{|c|}{ Mortality -38} \\
\hline $\mathrm{Z}$ & 0.909 & - & 0.205 & - & 0.871 & - & 0.097 & - & 0.272 & - & 0.365 & - \\
\hline $\mathrm{R}(Z)$ & 0.064 & - & 0.206 & - & 0.180 & - & • & - & . & - & 0.313 & - \\
\hline \multicolumn{13}{|l|}{ Main plot } \\
\hline $\bar{G}$ & 0.259 & - & 0.845 & - & 0.569 & - & 0.195 & - & 0.127 & - & 0.144 & - \\
\hline $\mathrm{G} \times \mathrm{Z}$ & 0.380 & - & 0.304 & - & 0.088 & - & 0.648 & - & 0.771 & - & 0.687 & - \\
\hline $\mathrm{G} \times \mathrm{R}(Z)$ & 0.031 & - & 0.031 & - & 0.031 & - & 0.004 & - & 0.004 & - & 0.031 & - \\
\hline
\end{tabular}

${ }^{a}$ Fixed effects: $\mathrm{Z}=$ zone, $\mathrm{G}=$ group, $\mathrm{G} \times \mathrm{Z}=$ interaction $\mathrm{G}$ by $\mathrm{Z}$. Random effects: $\mathrm{R}(\mathrm{Z})=$ replication in $\mathrm{Z}, \mathrm{G} \times \mathrm{R}(\mathrm{Z})=$ interaction $\mathrm{G}$ by $R(Z), P=$ provenance, $P \times Z=$ interaction $P$ by $Z, P \times R(Z)=$ interaction $P$ by $R(Z), P \times G=$ interaction $P$ by $G, F(P G)=$ family in $\mathrm{P}$ and $\mathrm{G}, \mathrm{F}(\mathrm{PG}) \times \mathrm{Z}$ = interaction $\mathrm{F}(\mathrm{PG})$ by $\mathrm{Z}, \mathrm{F}(\mathrm{PG}) \times \mathrm{R}(\mathrm{Z})$ = interaction $\mathrm{F}(\mathrm{G})$ by $\mathrm{R}(\mathrm{Z})$.

${ }^{\text {b }} \mathrm{P}=$ probability of $F$ ratio for fixed effects and $Z$ test for random effects. For $F$ ratios, $\mathrm{R}(\mathrm{Z})$ is the error for testing $Z$, and $\mathrm{G} \times \mathrm{R}(\mathrm{Z})$ is the error for testing $G$ and $G \times Z$. Degrees of freedom (Df) for $F$ ratios: $Z=2, R(Z)=7, G=1, G \times Z=2, G \times R(Z)=7$. For $Z$ tests, $\bullet$ indicates that the variance component equals zero. Total Df for height and diameter $=2407,2383$ and 2212 , respectively at 15, 26 and 38 months. Total Df for bifurcation and mortality $=19$ at each age.

${ }^{c} \mathrm{VC} \%$ = variance component expressed as a percentage of the total variance for random effects in the model except $\mathrm{R}(\mathrm{Z})$ and $\mathrm{G} x$ $\mathrm{R}(\mathrm{Z})$.

${ }^{d}$ Bifurcation and mortality: angular transformation of the proportion of trees in the selected and random groups in each replication.

Table 3. - Likelihood ratio chi-square $\left(G^{2}\right)$ test of independence between families of Calycophyllum spruceanum and the frequencies of stem bifurcations and tree mortality at 15, 26 and 38 months. Tests are given for all families and separately for families in the random and selected groups.

\begin{tabular}{lrrr}
\hline & All families & Random group & Selected group \\
\cline { 2 - 3 } \cline { 3 - 4 } \cline { 3 - 4 } & $\mathrm{P}^{\mathrm{a}}$ & $\mathrm{P}$ & $\mathrm{P}$ \\
\hline Stem bifurcations & & & 0.088 \\
15 months & 0.060 & 0.185 & 0.005 \\
26 months & 0.019 & 0.348 & 0.210 \\
38 months & 0.052 & & \\
Tree mortality & & 0.112 & 0.029 \\
15 months & 0.010 & 0.190 & 0.022 \\
26 months & 0.011 & 0.003 & 0.010 \\
38 months & $<0.001$ & & \\
\hline
\end{tabular}

a $\mathrm{P}=$ probability of $G^{2}$; degrees of freedom = 131 for all families, 65 for random and selected groups; number of trees at 15, 26 and 38 months, respectively = 1181, 1165 and 1049 for the random group, and 1227, 1219 and 1164 for the selected group. 
Table 4. - Family variance and coefficient of family variation of tree height and stem diameter of Calycophyllum spruceanum in the random and selected groups of trees at 15, 26 and 38 months.

\begin{tabular}{|c|c|c|c|c|}
\hline & \multicolumn{2}{|c|}{ Random group } & \multicolumn{2}{|c|}{ Selected group } \\
\hline & Family variance $(\mathrm{SE})^{\mathrm{a}}$ & Coefficient $\%{ }^{b}$ & Family variance (SE) & Coefficient $\%$ \\
\hline \multicolumn{5}{|l|}{ Tree height } \\
\hline 15 months & $0.038(0.014)$ & 6.9 & $0.056(0.016)$ & 7.7 \\
\hline 26 months & $0.120(0.046)$ & 7.7 & $0.128(0.038)$ & 7.6 \\
\hline 38 months & $0.146(0.068)$ & 6.3 & $0.087(0.048)$ & 4.8 \\
\hline \multicolumn{5}{|l|}{ Stem diameter } \\
\hline 15 months & $0.076(0.033)$ & 6.2 & $0.118(0.038)$ & 7.0 \\
\hline 26 months & $0.284(0.092)$ & 8.3 & $0.229(0.073)$ & 7.2 \\
\hline 38 months & $0.456(0.174)$ & 7.6 & $0.164(0.097)$ & 4.5 \\
\hline
\end{tabular}

${ }^{\text {a }}$ Family variance $=$ variance component due to families nested within provenance and group $\left(\sigma_{F(P G)}^{2}\right), \mathrm{SE}=$ standard error of variance component.

${ }^{\mathrm{b}}$ Coefficient $\%=$ coefficient of family variation $=\left(\sqrt{ } \sigma_{F(P G)}{ }^{2}\right) /($ group mean $)$ expressed as a percentage.

includes variances and covariances due to both parameters. Considering this and the overlap in the approximate confidence intervals mentioned above, we cannot conclude that the coefficients of family variation differ statistically between the two groups.

\section{Discussion}

\section{Variation in tree growth, form and mortality}

Phenotypic selection can be an effective means of securing genetic gain in timber trees under certain circumstances (CORNELIUS, 1994). The magnitude of the gain depends on the intensity of selection, the genetic variation present in the populations where selections are made, and the degree to which phenotype reflects genotype (i.e., the heritability of the trait). In this study, there are two reasons to expect modest genetic gains. First, selection intensity was low (approximately 1 out of 5 trees) and was based on several traits. Second, selections were made in highly heterogeneous farm environments and trees were not of the same age: under these circumstances, the phenotype is likely to be a poor guide to the genotype, at least for growth traits (NAMKOONG, 1970). In spite of this, phenotypic selection produced genetic gain in growth rate and survival of Calycophyllum spruceanum. In fact, the $10 \%$ observed gain in tree height and stem diameter at 15 months seems unexpectedly high. The actual realized gain in height and diameter may lie somewhere between the two extremes of $10 \%$ and $1 \%$ observed at 15 and 38 months, respectively. The decreasing difference in height and diameter between the selected and random groups over time may reflect the increasing difference in mortality between the groups, and the fact that dead trees were treated as missing values for calculating height and diameter. As inter-tree competition increases over time, the smaller, less vigorous trees suffer higher mortality than the larger, more vigorous trees. The random group had higher mortality than the selected group, so a larger proportion of the smaller trees died in the random group than in the selected group. Therefore, mean height and diameter of surviving trees increased more in the random than in the selected group due to mortality. Since the difference in mortality between groups increased from 15 to 38 months, the difference in mean height and diameter decreased between the groups. In addition, the estimated differences at all ages were probably affected by high environmental variation within and among replications produced by farmers' inconsistent weeding practices, as observed in other onfarm provenance/progeny tests (Sotelo Montes et al., 2006; RochON et al., 2007).

Results of this study are consistent with other studies demonstrating genetic variation in growth at an early age in tropical hardwoods in Latin America [e.g., Prosopis flexuosa D.C. (CONY, 1996); Alnus acuminata Kunth. (CoRNELIUs et al., 1996); Vochysia guatemalensis Sm., J.D. (CoRneliUs and MEsÉN, 1997); Sterculia apetala (Jacq.) Karst (DvorAK et al., 1998); Bombacopsis quinata (Jacq.) Dugand (Hodge et al., 2002); C. spruceanum (Sotelo Montes et al., 2006); Guazuma crinita Mart. (RocHON et al., 2007)]. Family means for height and diameter of $C$. spruceanum were relatively stable across zones, but there was considerable variance due to the interaction between families and replications, probably due to farmers' weeding practices (SOTELO MONTES et al., 2006).

Provenances did not account for significant variation in tree growth in this test, unlike another provenance/progeny test of C. spruceanum (SoTELO Montes et al., 2006). Both tests sampled the same provenances and were conducted in the same watershed. The difference probably reflects the fact that sample sizes were larger ( $>2$ times as many trees) and all progeny were from selected mother trees in the other test. In this test, progeny data from the random group lowered the provenance means, compared with the other test.

Results suggest that stem bifurcations and mortality of $C$. spruceanum also varied genetically, but this needs to be confirmed in future tests. Genetic variation in tree form has been reported for some other tropical hardwoods (CONY, 1996; CoRnelius et al., 1996; DvoraK et al., 1998), and the range in mortality among families in this test $(0-40 \%$ at 38 months in the selected group) was similar to that observed in another provenance/ progeny test of $C$. spruceanum (Sotelo Montes et al., 2006). Stem form and mortality, therefore, should be considered when selecting the best families for improvement programs for this species. 


\section{Family variance in growth traits in the selected and random groups}

Results suggest that the low-intensity selection strategy used in this study was effective in maintaining genetic variation in tree height and stem diameter in the selected population. Family variances in tree height and stem diameter and their coefficients of variation were lower in the selected than in the random group at 38 months but, given the overlap in their approximate confidence intervals, we cannot conclude that the differences were statistically significant. We recommend, therefore, that family variance should be evaluated in both groups for a longer period of time before making a definitive conclusion about the effectiveness of this selection strategy in maintaining genetic variation.

Estimating heritability was not an objective of this study, but the results are summarized for comparison with other studies. Individual tree heritability of tree height and stem diameter in this study (a) were similar in value, (b) did not differ significantly between the random and selected groups, judging from their standard errors, (c) increased slightly from 15 to 38 months, and (d) were comparable to estimates reported elsewhere for trees at similar ages (SotELo MonTEs et al., 2006).

\section{Practical implications and recommendations}

When farmers in the Peruvian Amazon wish to plant trees on their farms, they typically collect seed from a few selected trees (BRODIE et al., 1997). This practice should increase productivity in the planted population if the selection is based on traits that are under strong genetic control and have a lot of variability (FALCONER and MACKAY, 1996). However, the limited genetic base in the planted population puts it at a higher risk if environmental conditions change, and it reduces options for future selections on farm (Simons et al., 1994). Moreover, if the selected trees are genetically related, this practice may actually lower productivity in the long term due to inbreeding depression. In response to these concerns, it was recommended that farmers and tree improvement programs select a large number of trees on farms using low selection intensities (O'NeILL et al., 2001). Based on this study, the low-intensity selection strategy appears to maintain genetic variation in the selected population and produces modest genetic gains in growth and survival through approximately 3 years, which corresponds to the harvest age for construction poles. If possible, evaluations should continue to assess genetic variation and gains over a period of time that corresponds to the harvest age for sawn timber.

Without increasing the selection intensity, gains in growth and some wood properties in some species could be increased by selecting trees based on wood traits that have a higher heritability than growth traits and are positively correlated with growth. For example, wood density has a higher heritability than tree height and stem diameter in C. spruceanum, and there is a positive genetic correlation between density and these growth traits (SOTELo MonTEs et al., 2006). In addition, genetic correlations indicate that $C$. spruceanum wood with higher density is stronger and stiffer, but has slightly greater volumetric shrinkage (SOTELO MONTES et al., 2007a, 2007b). Therefore, selecting C. spruceanum trees with denser wood, based on non-destructive methods, could simultaneously increase wood density, strength, stiffness and tree growth in the next generation, but it would slightly increase wood shrinkage. These relationships should be investigated in other tropical timbertree species, and used to develop more effective selection strategies.

Tree improvement programs must consider the tradeoff between genetic variation and genetic gain (CoRNELIUS et al., 2006), and the uncertainty about future environments and markets. In well-funded industrial programs, highly intensive selection and flexibility may be simultaneously secured through multiple breeding populations and other long-term breeding strategies. In smallholder contexts, however, funding tends to be low and fluctuating, genetic variation cannot be easily managed pro-actively, and the release of highly selected first-generation material could rapidly lead to the accumulation of inbreeding in production populations with consequent decreases in productivity. Therefore, alternative approaches are needed. A village-level, participatory domestication program based on the selection of unrelated clones in each village is a very attractive approach for smallholders because it has the potential to produce high genetic gain and conserve genetic variation at the inter-village level (LEAKEY et al., 2003; SimONS and LEAKEY, 2004). However, the avoidance of inbreeding is still dependent on proper use of the selected clonal material. For example, if farming communities continue to propagate and plant only a few selected clones, then inbreeding will pose a problem. A pro-active strategy would involve discussing the negative effects of inbreeding with farming communities; encouraging them to propagate, plant and conserve many (e.g., 30-50) genetically unrelated clones in each village; and organizing networks to exchange packages of genetically unrelated clones among villages in each region (DAWSON et al., 2008).

The approach described in this paper provides farmers with highly variable material of slightly improved genetic quality, and sacrifices short-term genetic gain in favor of longer-term flexibility. This strategy will not satisfy all farmers in the short term but, given the economic and environmental uncertainties facing farmers in the future and the low level of funding available for smallholder tree improvement, we believe that it is an appropriate strategy for minimizing risk.

\section{Acknowledgements}

This research was supported by grants to the World Agroforestry Centre (ICRAF) from the Interamerican Development Bank, the Government of Spain, the Governments of Netherlands and Norway as part of the CGIAR Global Initiative for Alternatives to Slash and Burn, the Department for International Development of the United Kingdom, and Winrock International as part of the USAID Alternative Development Program. We wish to thank the participating farmers and technicians who worked on this project, NANCY MANDEL (U.S.D.A. Forest 
Service) and RICHARD COE (ICRAF) for statistical advice, Jonathan CoRnelius (James Cook University) and two anonymous reviewers for their constructive comments.

\section{References}

Boivin-Chabot, S., H. A. Margolis and J. C. Weber (2004): Variation in coppice-shoot growth among provenances of Calycophyllum spruceanum Benth. in the Peruvian Amazon Basin. Forest Ecology and Management 198: 249-260.

Brodie, A. W., R. A. Labarta Chávarri and J. C. Weber (1997): Tree germplasm management and use on-farm in the Peruvian Amazon: a case study from the Ucayali region, Peru. Research report, Overseas Development Institute, London, and International Centre for Research in Agroforestry, Nairobi.

Cony, M. A. (1996): Genetic variability in Prosopis flexuosa D.C., a native tree of the Monte phytogeographic province, Argentina. Forest Ecology and Management 87: 41-49.

CoRnelius, J. (1994): The effectiveness of plus-tree selection for yield. Forest Ecology and Management 67: 23-34.

Cornelius, J., F. Mesén, E. Corea and M. Henson (1996): Variation in growth and form of Alnus acuminata Kunth. grown in Costa Rica. Silvae Genetica 45: 24-30.

CoRnelius, J. and F. MEsÉn (1997): Provenance and family variation in growth rate, stem straightness, and foliar mineral concentration in Vochysia guatemalensis. Canadian Journal of Forest Research 27: 1103-1109.

Cornelius, J., C. R. Clement, J. C. Weber, C. SoteloMontes, J. van Leeuwen, L. J. Ugarte-Guerra and L. ARÉVALO-LóPEz (2006): The trade-off between genetic gain and conservation in a participatory improvement programme: the case of peach palm (Bactris gasipaes Kunth). Forest, Trees and Livelihoods 16: 17-34.

Dawson, I. K., A. Lengkeek, J. C. Weber and R. JAMNADASS (2008): Managing genetic variation in tropical trees: linking knowledge with action in agroforestry ecosystems for improved conservation and enhanced livelihoods. Biodiversity and Conservation On line: DOI 10.1007/s10531-008-9516-z

Dvorak, W. S., H. Urueña, L. A. Moreno and J. Goforth (1998): Provenance and family variation in Sterculia apetala in Colombia. Forest Ecology and Management 111: $127-135$.

FAlCONER, D. S. and T. F. C. MACKaY (1996): Introduction to Quantitative Genetics. Addison Wesley Longman Limited, Edinburgh.

Hodge, G. R., W. S. Dvorak, H. Urueña and L. Rosales (2002): Growth, provenance effects and genetic variation of Bombacopsis quinata in field tests in Venezuela and Colombia. Forest Ecology and Management 158: 273-289.

LeAkey, R. R. B., K. Schreckenburg and Z. TChoundjeu (2003): The participatory domestication of West African indigenous fruits. International Forestry Review 5: 338-347.

Linares, C., E. Meneses and J. Diaz (1992): Monografía sobre capirona: Calycophyllum spruceanum. Proyecto Forestal ITTO PD 37/88 Utilización industrial de nuevas especies forestales en el Perú, Cámara Nacional Forestal, Dirección General de Forestal y Fauna, Lima.

NAMKOONG, G. (1970): Optimum allocation of selection intensity in two stages of truncation selection. Biometrics 26: $476-476$.
Oehlert, G. W. (2000): A First Course in Design and Analysis of Experiments. Freeman, New York.

O’Neill, G. A., I. K. Dawson, C. Sotelo Montes, L. Guarino, D. Current, M. Guariguata and J. C. Weber (2001): Strategies for genetic conservation of trees in the Peruvian Amazon basin. Biodiversity and Conservation 10: 837-850.

Rochon, C., H. A. Margolis and J. C. Weber (2007): Genetic variation in growth of Guazuma crinita (Mart.) trees at an early age in the Peruvian Amazon. Forest Ecology and Management 243: 291-298.

SAS INSTITUTE INC. (2004): SAS/STAT Users' Guide, Version 9.1. SAS Institute Inc., Cary.

SEARS, R. R. (2003): New forestry on the floodplain: the ecology and management of Calycophyllum spruceanum (Rubiaceae) on the Amazon landscape. Ph.D. dissertation, Graduate School of Arts and Sciences, Columbia University, Ithaca.

Simons, A. J., D. J. MACQueen and J. L. Stewart (1994): Strategic concepts in the domestication of non-industrial trees, p.p. 91-102. In: Tropical trees: the potential for domestication and the rebuilding of forest resources, edited by R. R. B Leakey and A. C. Newton, HMSO, London.

Simons, A. J. and R. R. B. LEAKEY (2004): Tree domestication in tropical agroforestry. Agroforestry Systems 61: $167-181$.

Sotelo Montes, C., H. Vidaurre and J. C. Weber (2003): Variation in stem-growth and branch-wood traits among provenances of Calycophyllum spruceanum Benth. from the Peruvian Amazon. New Forests 26: $1-16$.

Sotelo Montes, C., R. Hernández, J. Beaulieu and J. C. WEBER (2006): Genetic variation and correlations between growth and wood density of Calycophyllum spruceanum Benth. at an early age in the Peruvian Amazon. Silvae Genetica 55: 217-228.

Sotelo Montes, C., J. Beaulieu and R. Hernández (2007a): Genetic variation in wood mechanical properties, and their correlations with tree growth and wood density of Calycophyllum spruceanum at an early age in the Peruvian Amazon. Wood and Fiber Science 39: 377-387.

Sotelo Montes, C., J. Beaulieu and R. Hernández (2007b): Genetic variation in wood shrinkage, and its correlations with tree growth and wood density of Calycophyllum spruceanum at an early age in the Peruvian Amazon. Canadian Journal of Forest Research 37: 966-976.

Sotelo Montes, C., R. Hernández, J. Beaulieu and J. C. WEBER (2008): Genetic variation in wood color and its correlations with tree growth and wood density of Calycophyllum spruceanum Benth. at an early age in the Peruvian Amazon. New Forests 35: 57-73.

Toledo, E. and C. Rincón (1996): Utilización industrial de nuevas especies forestales en el Perú. Cámara Nacional Forestal, Instituto Nacional de Recursos Naturales, Organización Internacional de las Maderas Tropicales, Lima.

Weber, J. C., C. Sotelo Montes, H. Vidaurre, I. K. DaWSON and A. J. Simons (2001): Participatory domestication of agroforestry trees: an example from the Peruvian Amazon. Development in Practice 11: 425-433.

WeBer, J. C. and C. Sotelo Montes (2005): Variation and correlations among stem growth and wood traits of Calycophyllum spruceanum Benth. from the Peruvian Amazon. Silvae Genetica 54: 31-41. 